\title{
Body Composition Influences Post-Operative Complications and 90-Day and Overall Survival in Pancreatic Surgery Patients
}

\author{
Sónia Velho ${ }^{a}$ Maria Pia Costa Santos ${ }^{b}$ Cátia Cunha $^{c}$ Lisa Agostinho ${ }^{d}$ \\ Rita Cruz ${ }^{d}$ Filipe Costa $^{\text {e }}$ Mafalda Garciac Paulo Oliveirac Rui Maioc, e \\ Vickie E. Baracos ${ }^{f}$ Marília Cravo ${ }^{b, e, g}$ \\ a Dietetics and Nutrition, Hospital Beatriz Ângelo, Loures, Portugal; b Gastroenterology, Hospital Beatriz Ângelo, \\ Loures, Portugal; ' Surgery, Hospital Beatriz Ângelo, Loures, Portugal; ${ }^{d}$ Radiology, Hospital Beatriz Ângelo, Loures,

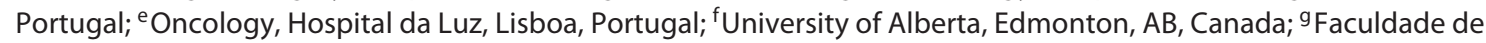 \\ Medicina da Universidade de Lisboa, Lisboa, Portugal
}

\section{Keywords}

Pancreatic surgery · Body composition - Survival ·

Postoperative complications - Muscle attenuation · Ratio of visceral fat area/skeletal muscle area

\section{Abstract}

Introduction: Pancreatic surgery still carries a high morbidity and mortality even in specialized centers. The aim of this study was to evaluate the influence of patients' body composition on postoperative complications and survival after pancreatic surgery. Methods: This was a retrospective study on patients undergoing pancreatic surgery between March 2012 and December 2017. Demographics, clinical data, and postoperative complications classified according to Clavien-Dindo were recorded. Body composition was assessed using routine diagnostic or staging computed tomography (CT). Multiple Cox proportional hazards models were adjusted. Results: Ninety patients were included, 55\% were

karger@karger.com www.karger.com/pjg

\section{Karger $\stackrel{\text { ! }}{=}$}

GOPEN ACCESS
(C) 2020 Sociedade Portuguesa de Gastrenterologia Published by S. Karger AG, Basel

This article is licensed under the Creative Commons AttributionNonCommercial-NoDerivatives 4.0 International License (CC BYNC-ND) (http://www.karger.com/Services/OpenAccessLicense). Usage and distribution for commercial purposes as well as any distribution of modified material requires written permission. male, and the mean age was $68 \pm 10.9$ years. Of these 90 , $92 \%$ had a total pancreatectomy or pancreaticoduodenectomy, $7 \%$ a distal pancreatectomy, and $1 \%$ a pancreaticoduodenectomy with multi-visceral resection; $84 \%$ had malignant disease. The incidence of major complications was $27.8 \%$ and the 90 -day mortality was $8.8 \%$. The ratio of visceral fat area/skeletal muscle area (VFA:SMA) was associated with an increased risk of complications (OR 2.24, 95\% Cl $1.14-4.87, p=0.03$ ) and 90-day survival (HR 2.13,95\% Cl $1.13-4.01, p=0.019)$. On simple analysis, shorter overall survival (OS) was observed in patients aged $\geq 70$ years $(p=$ $0.0009)$, with postoperative complications $\geq$ IIIb $(p=0.01)$, an increased VFA:SMA ( $p=0.007)$, and decreased muscle radiation attenuation $\left(p=1.6 \times 10^{-5}\right)$. In an OS model adjusted for age, disease malignancy, postoperative complications, and body composition parameters, muscle radiation attenuation remained significantly associated with survival (HR 0.94, 95\% Cl 0.90-0.98, $p=0.0016)$. A model which included only body composition variables had a discrimina- 
tion ability ( $C$-statistic 0.76 ) superior to a model which comprised conventional clinical variables ( $C$-statistic 0.68 ). Conclusion: Body composition is a major determinant of postoperative complications and survival in pancreatic surgery patients.

(c) 2020 Sociedade Portuguesa de Gastrenterologia Published by S. Karger AG, Basel

\section{A composição corporal influencia a taxa de complicações pós-operatórias, a sobrevivência aos 90 dias e global em doentes submetidos a cirurgia pancreática}

\section{Palavras Chave}

Cirurgia pancreatica · Composição corporal ·

Sobrevivência · Complicações pós-operatórias .

Atenuação muscular · Racio da área de gordura visceral / área de tecido muscular esquelético

\section{Resumo}

Introdução: A cirurgia pancreática continua associada a uma elevada morbimortalidade mesmo em centros de referência. $\mathrm{O}$ objetivo do presente estudo foi avaliar a influência da composição corporal nas complicações e sobrevivência após cirurgia pancreática. Métodos: Estudo retrospetivo em doentes submetidos a cirurgia pancreática entre Março 2012 e Dezembro 2017. Foram registadas variáveis demográficas, clínicas, complicações pós-cirúrgicas classificadas de acordo com a classificação de a classificação de Clavien Dindo. A composição corporal foi avaliada utilizando imagens de Tomografia Axial Computorizada (TAC) realizada no diagnóstico. Modelos de riscos porporcionais de Cox foram ajustados. Resultados: Incluídos 90 doentes, 55\% homens e média de idade de $68 \pm 10.9$ anos; $92 \%$ submetidos a pancreatectomia/pancreatoduodenectomia, 7\% pancreatectomia distal e $1 \%$ pancreatoduodenectomia com ressecção multivisceral; $84 \%$ tinham doença maligna. A incidência de complicações major foi de $27.8 \%$ e a mortalidade aos 90 dias de 8.8\%. O racio da Área de Gordura Visceral (AGV) / Área de Tecido Muscular Esquelético (ATME) associou-se a um risco acrescido de complicações (OR 2.24, 95\% Cl 1.14-4.87, $p=0.03$ ) e de morte aos 90 dias (HR 2.13, 95\% Cl 1.13-4.01, $p=0.019)$. Observámos uma sobrevivência global mais baixa em doentes com idade $\geq 70$ anos $(p=0.0009)$, com complicações $\geq$ IIIb ( $p=0.01$ ), com AGV/ ATME aumentada e atenuação muscular diminuída $\left(p=1.6 \times 10^{-5}\right)$. A atenuação muscular ajustada para a idade, malignidade, complicações, manteve-se associada à sobrevivência global (HR 0.94, IC 95\% 0.90-0.98, $p=0.0016)$. Um modelo que inclua apenas variáveis de composição corporal mostrou uma capacidade discriminatória (C-statistic 0.76) superior a um modelo convencional com variáveis clínicas (C-statistic 0.68). Conclusão: A composição corporal é um determinante major de complicações pós-cirúrgicas e de sobrevivência de doentes submetidos a cirurgia pancreática.

(c) 2020 Sociedade Portuguesa de Gastrenterologia Publicado por S. Karger AG, Basel

\section{Introduction}

Pancreatic cancer incidence is increasing, and surgery remains the only curative treatment. However, even in specialized centers, the incidence of postoperative complications remains as high as $40-60 \%$ with a 5 -year survival rate of $10-20 \%$ [1].

Operative mortality has improved through surgical technique and perioperative care optimization. In particular, the enhanced recovery after surgery (ERAS) pathway allows a standardized, multimodal, multidisciplinary approach aimed at favoring postoperative recovery by reducing surgical metabolic stress and limiting organ dysfunction [2].

With regard to nutritional status, recent studies have suggested that body composition phenotypes may influence postoperative and long-term clinical outcomes. Most studies have focused primarily on the impact of sarcopenia (low skeletal-muscle mass) on major postoperative complications [3] and overall survival (OS) [1, 4-12], and secondarily on visceral adipose tissue $[3,8,10,13]$ and low muscle radiation attenuation (a marker of fat infiltration of skeletal muscle) [9-11, 13]. Although some of these studies have included body mass index (BMI) [4, 12] as a proxy of body fatness, the influence of skeletal muscle infiltration by adipose tissue as well as the proportion of visceral adipose tissue with regard to skeletal-muscle tissue has been strikingly less studied.

Bearing in mind that obesity is a recognized risk factor for pancreatic cancer and that many of these patients experience weight loss at diagnosis which will certainly translate into a decline of skeletal muscle mass, we hypothesized that all tissues, namely skeletal muscle, visceral fat, and skeletal muscle infiltration by adipose tissue, may be equally relevant. We believe that this approach could lead us to a more comprehensive view where all tissues have a different role but are equally important and expected to interplay. We therefore aimed 
to study the association of body composition parameters, i.e., skeletal muscle, visceral fat, and muscle radiation attenuation with postoperative complications, 90 day survival, and OS in patients undergoing pancreatic surgery.

\section{Materials and Methods}

We conducted a single-center retrospective study at the Beatriz Ângelo Hospital (HBA). We reviewed all patients undergoing pancreatic surgery at our hospital between March 2012 and December 2017. To be eligible for our study, patients needed to have an abdominal computed tomography (CT) scan performed at our institution within 30 days of surgery to allow body composition analysis.

Demographic and clinical data including age, gender, American Society of Anesthesiologists (ASA) score, disease location, and histology according to surgical specimens were retrieved from patients' electronic charts. The 90-day mortality and postoperative complications were classified according to Clavien-Dindo classification. We considered the rate of complications as grade I-IIIa versus grade IIIb-V [14]. The date of the last follow-up and death were recorded as well. Primary outcome was OS measured in months from the date of elective hospitalization for surgery until death or until the censor date of the last visit to the hospital. The 90-day survival was recorded in months from the date of elective hospitalization for surgery until death or until the censor date set at 90 days after surgery.

\section{Body Composition Assessment}

Weight and reported height were recorded on admission and body mass index (BMI) was computed. BMI classification was done according to the following categories for adults: $<18.5=$ underweight, $18.5-24.9=$ normal weight, $25.0-29.9=$ overweight, $30.0-34.9=$ class I obesity, $35-39.9=$ class II obesity, and $\geq 40=$ class III obesity. The BMI classification for the elderly was used for patients aged $\geq 65$ years, i.e., $<24=$ underweight, $24-27=$ normal weight, and $>27=$ overweight. Opportunistic body composition assessment was conducted from the diagnostic or staging CT scan. CT methodology is highly precise for quantifying specific tissues and predicting whole-body composition [15]. Images were selected by radiologists on the axial plane at the level of the 3rd lumbar vertebra including both transverse processes using a portal venous phase, and then processed with a program built with Matlab. This software performs an automatic segmentation of tissue cross-sectional areas, using the following Hounsfield unit (HU) thresholds: -29 to 150 for skeletal muscle, -190 to -30 for subcutaneous and intramuscular adipose tissue, and -50 to -150 for visceral adipose tissue. Validation of the processed images was conducted and manual corrections were executed by radiologists. Cross-sectional skeletal muscle, visceral fat, subcutaneous fat, and mean muscle radiation attenuation were recorded. The skeletal muscle index (SMI $\left[\right.$ in $\left.\mathrm{cm}^{2} / \mathrm{m}^{2}\right]=$ skeletal muscle area [SMA]/height) and ratio of visceral fat area/SMA (VFA:SMA) were calculated as previously described $[3,16]$. Sarcopenia, low muscle radiation attenuation, and high visceral fat were defined according to sex-specific previously published cut-offs $[16,17]$.

Body Composition and Pancreatic Surgery

\section{Statistical Analysis}

The thresholds for CT image-derived body composition parameters to define sarcopenia and low muscle radiation attenuation have been determined for a population with mixed cancer disease locations $[16,18]$ whereas those for visceral obesity have been obtained from obesity-related research $[19,20]$. The abovementioned thresholds for sarcopenia and low muscle radiation attenuation have already been used in pancreatic cancer patients [ 3 , $4,12,13,21,22]$. Besides this, candidate thresholds for sarcopenia based on SMA/body surface area (BSA) have been determined for gastric cancer patients [23]. However, there has been some criticism about the generalization of the reported thresholds due to ethnic and disease-site differences. As such, in recent studies with pancreatic cancer patients, different strategies to determine specific thresholds for each study population have been used, such as optimal stratification of total psoas area [5], sex-specific lowest quartile/tertile of SMA $[9,10]$, and receiver-operating characteristics (ROC) curve analysis $[6,11]$.

Since no thresholds for body composition have yet been established for the Portuguese population and bearing in mind that using thresholds not validated specifically for patients with pancreatic tumors may be misleading, we decided to use body composition variables in their continuous form, except for the Kaplan-Meier curves comparison, where dichotomization is necessary. From a statistical point of view, the use of continuous variables is a better option than discrete data, since continuous data convey more information. However, to account for gender-specific differences in body composition, variables were mean-centered in order to be scaled by sex. We decided not to use optimal stratification strategies, since this approach was considered unstable for our sample size.

Simple and multiple logistic regression were used to relate each variable with complications as Clavien-Dindo $\geq$ IIIb. For continuous variables, linearity of the logit in the predictor was assessed using a cubic spline and the Wald test of linearity [24]. Only variables with a $p$ value $\leq 0.25$ or considered clinically relevant were selected for multiple logistic regression. Multicollinearity was also analyzed via the observation of variance inflation factors. A stepwise bothselection technique was used to create the multiple regression model. The ROC curve was computed and the respective area under the curve (AUC) was calculated to assess the accuracy of the model. The positive and negative predictive values (PPV and NPV) were also given. The association between major postoperative complications and type of surgery was assessed with the Fisher exact test.

Survival analysis was conducted with the Kaplan-Meier estimate, and survival curves were compared with the log-rank test. Body composition variables such as SMI and muscle radiation attenuation were dichotomized according to the lowest sex-specific quartile and VFA:SMA, with respect to the highest sex-specific quartile to allow for the comparison of survival curves.

First, 2 multiple Cox proportional hazards models with conventional clinical variables and body composition variables were adjusted and the $C$-statistic was computed to assess model prediction ability.

Lastly, a multiple Cox proportional hazards model was adjusted for 90-day survival, in order to allow the comparison between variables associated with 90-day survival and OS. In this comparison, we used the OS model containing both clinical and body composition variables which yielded the highest $C$-statistics.

Data analysis was performed with SPSS v20 and $R$ v3.0.2 and statistical significance was set at $p \leq 0.05$.

GE Port J Gastroenterol 2021;28:13-25 
Table 1. Demographic and clinical data of 90 patients

\begin{tabular}{lc}
\hline Age, years (mean \pm SD) & $68 \pm 10.9$ \\
Male sex & $50(56)$ \\
ASA grade & \\
$\quad$ I/II & $60(66.6)$ \\
$\quad$ III & $30(33.3)$ \\
Preoperative biliary drainage & $38(42.2)$ \\
Type of surgery & \\
$\quad$ Duodenopancreatectomy/total & $84(92)$ \\
$\quad$ Distal resection body-tail & $6(7)$ \\
$\quad$ Duodenopancreatectomy with multivisceral & \\
$\quad$ resection & $1(1)$ \\
Postoperative histology & $26(54)$ \\
$\quad$ Benign & $14(16)$ \\
$\quad$ Malignant & $76(84)$ \\
$\quad$ Stage I & $22(28.9)$ \\
$\quad$ Stage II/III & $54(71.1)$ \\
Preoperative chemotherapy & $9(10.0)$ \\
Major postoperative complications & $25(27.8)$ \\
90-Day mortality & $8(8.8)$ \\
Overall mortality & $26(28.9)$
\end{tabular}

Values express $n(\%)$, unless otherwise indicated.
Table 2. BMI and body composition of 90 patients at diagnosis

$\begin{array}{lc}\text { BMI } & 25(27.8) \\ \text { Underweight } & 34(37.8) \\ \text { Normal weight } & 18(20.0) \\ \text { Overweight } & 12(13.3) \\ \text { Class I obesity } & 1(1.1) \\ \text { Class II obesity } & \\ \text { SMI } & 49.4 \pm 8.2 \mathrm{~cm}^{2} / \mathrm{m}^{2} \\ \text { Men } & 41.2 \pm 4.9 \mathrm{~cm}^{2} / \mathrm{m}^{2} \\ \text { Women } & 105.3 \pm 50.3 \mathrm{~cm}^{2} / \mathrm{m}^{2} \\ \text { Fat mass index } & 139.3 \pm 66.8 \mathrm{~cm}^{2} / \mathrm{m}^{2} \\ \text { Men } & \\ \text { Women } & 58.6 \pm 32.2 \mathrm{~cm}^{2} / \mathrm{m}^{2} \\ \text { Visceral fat index } & 51.6 \pm 33.6 \mathrm{~cm}^{2} / \mathrm{m}^{2} \\ \quad \text { Men } & \\ \text { Women } & 34.8 \pm 7.9 \mathrm{HU}^{2} \\ \text { Muscle radiation attenuation } & 30.8 \pm 10.0 \mathrm{HU}^{2} \\ \text { Men } & \\ \text { Women } & 1.2 \pm 0.6 \\ \text { VFA:SMA } & 1.2 \pm 0.9 \\ \text { Men } & \end{array}$

Values are expressed as $n$ (\%) or mean (SD). BMI, body mass index; SMI, skeletal muscle index; FMI, fat mass index; VFA:SMA, ratio of visceral fat area/skeletal muscle area.

pancreaticoduodenectomy with multivisceral resection. The rate of major complications was $27.8 \%$, the 90 -day mortality rate was $8.8 \%$, and $28.9 \%$ died during the study period. Survival was $81.1 \%$ at 1 year and $73.3 \%$ at 2 years. The mean follow-up period was $12.5(0.26-49.8)$ months.

BMI categories and body composition parameters at diagnosis are presented in Table 2 . The number of patients per body composition phenotype according to published cut-offs is shown in Figure 1. Mean BMI was 25.1 $\pm 4.03 ; 27.8 \%$ of the patients were underweight, $37.8 \%$ were of normal weight, $20.0 \%$ were overweight, $13.3 \%$ had class I obesity, and $1.1 \%$ had class II obesity. Furthermore, $2.2 \%$ patients presented sarcopenic obesity.

\section{Postoperative Complications}

Twenty-five of 90 patients had postoperative complications $\geq$ IIIb. We observed that 24 of these 25 patients were referred for total pancreatectomy or pancreaticoduodenectomy, 1 for pancreaticoduodenectomy with multivisceral resection, and none for distal resection experienced major complications. In this analysis, we obtained a near-significant association between the type of surgery and major postoperative complications ( $p=$ 0.087 ). Table 3 shows simple and multiple logistic regressions exploring the association of each variable with the
16

GE Port J Gastroenterol 2021;28:13-25 DOI: $10.1159 / 000507206$
Velho et al. 
Table 3. Simple and multiple logistic regression with postoperative complications as the dependent variable

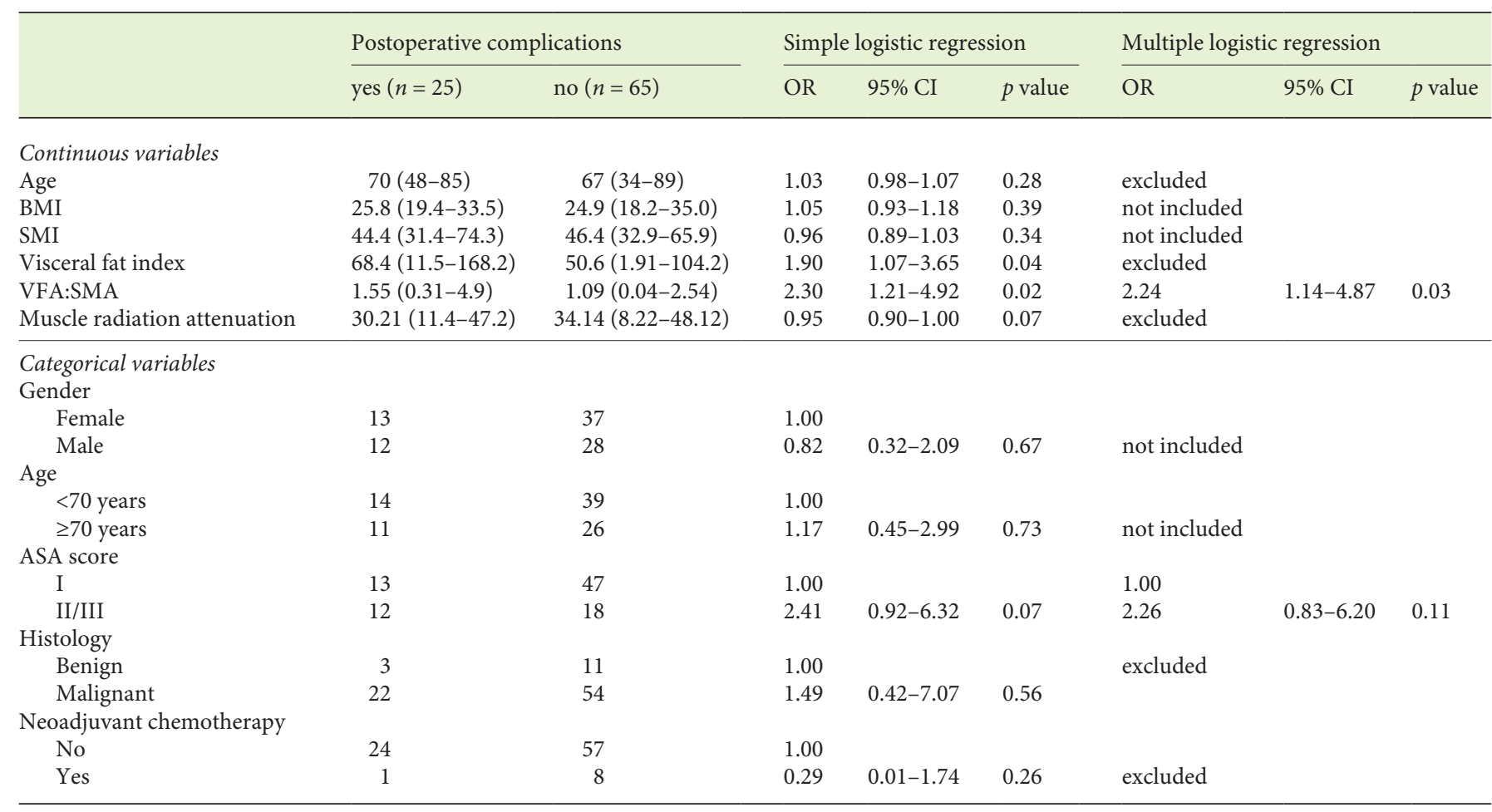

Values are presented as mean (range) or $n$. "Excluded" pertains to variables excluded in the stepwise analysis and "not included" to variables not included since $p>0.25$. BMI, body mass index; SMI, skeletal muscle index; VFA:SMA, ratio of visceral fat area/skeletal muscle area.

postoperative complications. Simple logistic regression showed that postoperative complications $\geq$ IIIb were significantly associated with the visceral fat index and VFA:SMA, and an almost significant association was found for muscle radiation attenuation and ASA score. However, in the multiple logistic regression analysis, only VFA:SMA remained significantly associated with postoperative complications $\geq \mathrm{III}$. In this model, the odds of major complications were 2-fold greater per (an increase of 1) unit of VFA:SMA. Regarding ASA score, although it was perceived as relevant to major postoperative complications (since it was selected in the stepwise analysis), it lost statistical significance when adjusted for VFA:SMA. The AUC obtained through the ROC curve analysis was 0.691 , which shows a fair discrimination ability of the selected model (Fig. 2). Sensitivity was $68.0 \%$, specificity was $67.7 \%$, PPV was $15.4 \%$, and NPV was $55.3 \%$. Lastly, we conducted a subset analysis includingonly patients with malignant disease, where VFA:SMA was the only variable to be selected for the final model with a near-significant association (OR 1.77, 95\% CI $0.925-3.77, p=0.10)$.

Body Composition and Pancreatic Surgery

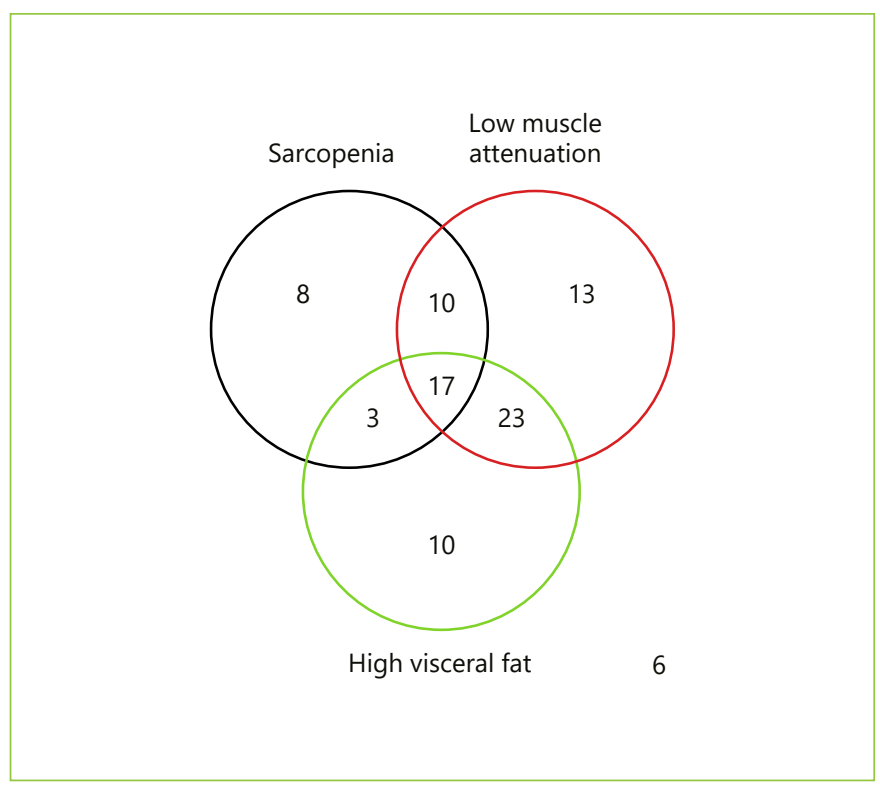

Fig. 1. Venn diagram of number of patients with sarcopenia, low muscle attenuation, and high visceral fat defined with published cut-offs $(n=90)$. 


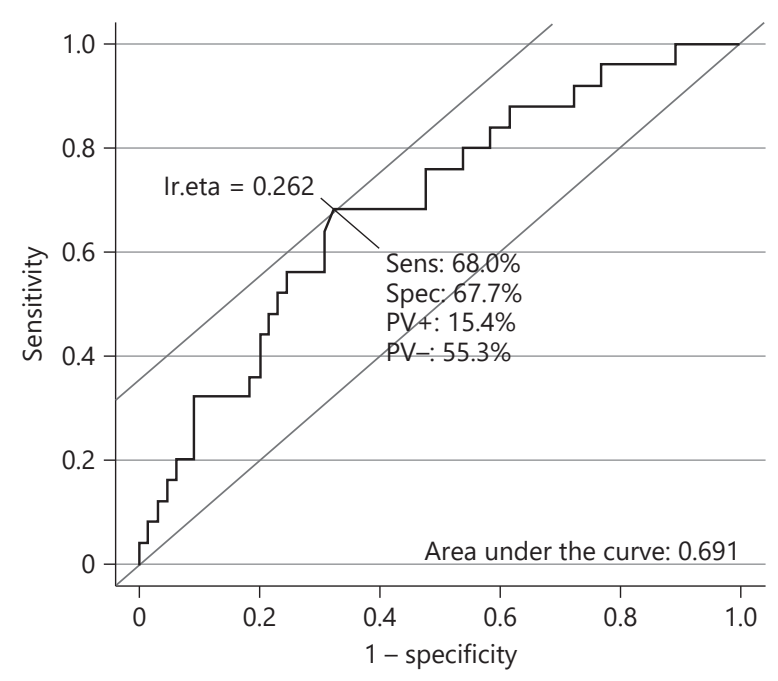

Fig. 2. Receiver-operating characteristics (ROC) curve for major complications as the dependent variable and ASA score and ratio of visceral fat area/skeletal muscle area as independent variables $(n=90)$. Sens, sensitivity; Spec, specificity; $\mathrm{PV}+$, positive predictive value; $\mathrm{PV}-$, negative predictive value.

\section{Survival}

Estimated mean OS was 31.15 months. Kaplan-Meier survival curves for OS as well as their comparison with clinical and body composition variables are reported in Figures 3-5. Dichotomization of body composition parameters was conducted using the first sex-specific quartile for SMI (males $43.9 \mathrm{~cm}^{2} / \mathrm{m}^{2}$ and females $37.2 \mathrm{~cm}^{2}$ / $\mathrm{m}^{2}$ ), muscle radiation attenuation (males $30.9 \mathrm{HU}$ and females $23.42 \mathrm{HU}$ ), and the third sex-specific quartile for the VFA:SMA (males 1.52 and females 1.67) to allow for the Kaplan-Meier curves comparison. Comparison of survival curves was also conducted for BMI categories (low/normal weight vs. overweight/obese), but no statistically significant differences were found $(p=0.332)$.

Table 4 presents the results of the simple and multiple analyses for OS. Regarding clinical variables, in the simple analysis, shorter survival was observed in patients aged $\geq 70$ years, those submitted to pancreaticoduodenectomy with multivisceral resection, with postoperative complications $\geq \mathrm{IIIb}$, and when a near-significant $p$ value was found for ASA score (I/II vs. III). Regarding body composition variables, an increase of 1 unit in muscle radiation attenuation was associated with an $8 \%$ reduction in the estimated risk of death, whereas an increase of 1 unit in VFA:SMA was associated with an increase of $90 \%$ in the estimated risk of death. Lastly, a near-significant association was found between OS and SMI, where an increase of 1 unit was associated with a $5 \%$ reduction in the estimated risk of death.

Two multiple proportional hazards Cox models were adjusted using variables significantly associated with OS or considered clinically pertinent, and the $C$-statistics were compared. In the first model, only conventionally used clinical variables were included, namely age, ASA score, histology, and postoperative complications. In this model, both age and postoperative complications were significantly associated with OS. The estimated risk of death was 3.34 times greater in patients aged $\geq 70$ years. HRs for major complications could not be computed because this variable was adjusted by stratification as it violated the proportional hazards assumption. At first, we decided not to include the type of surgery because most patients were submitted to total pancreatectomy or pancreaticoduodenectomy, and there were very few patients who underwent distal pancreatectomy and multivisceral resection which can influence estimates. However, bearing in mind the clinical relevance of this variable, we performed the same analysis including the type of surgery; this did not alter the previous results or increase the performance of the model (the $C$-statistics remained the same), so we decided to not include it after all to avoid overfitting (data not shown). A second model was adjusted using body composition variables. In this model, we included SMI, muscle radiation attenuation, and VFA: SMA. The only significant variable was muscle radiation attenuation, where an increase of $1 \mathrm{HU}$ was associated with an $8 \%$ reduction in estimated risk of death. Interestingly, the model which included 3 body composition variables had a discrimination ability (a C-statistic of 0.76 ) superior to the model which included 4 conventional clinical variables (a $C$-statistic of 0.68 ).

To compare postoperative survival with OS, Table 5 shows the results obtained for the model that yielded the highest $C$-statistics with regard to OS and the results of the Cox proportional hazards model for the analysis of 90 -day survival. Ninety-day survival was associated with age, with patients aged $\geq 70$ years displaying an 8.2 -fold greater estimated risk of postoperative death compared with patients aged $<70$ years. Although in this analysis we could not compute the HR for postoperative complications $\geq$ IIIb due to model stratification, it is worth noting that all patients who had died at 90 days had experienced major complications. Also, the estimated risk of death was 2 times higher per (an increase of 1) unit of VFA:SMA adjusted for age, histology, and postoperative complications.
Velho et al. 

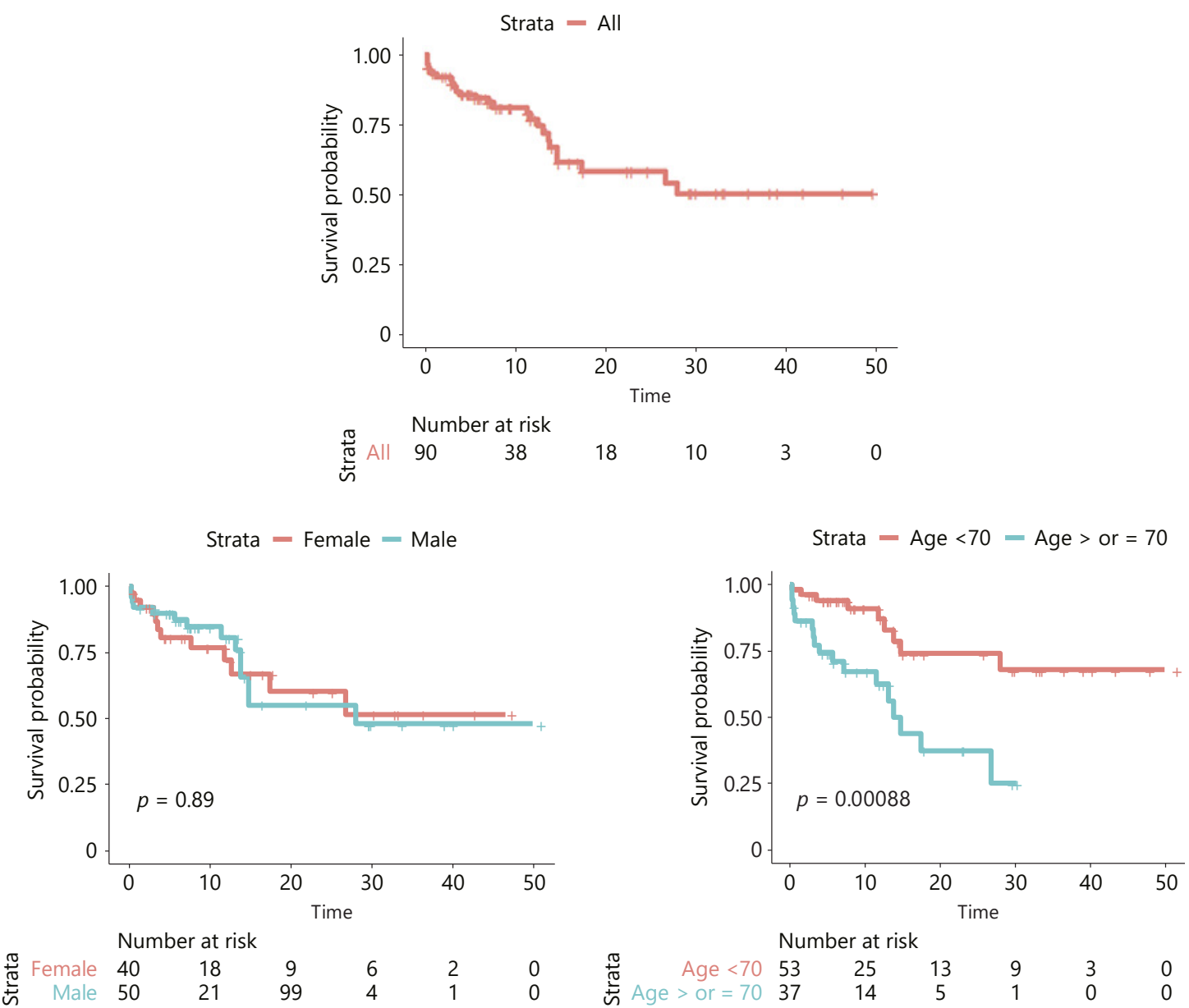

Number at risk

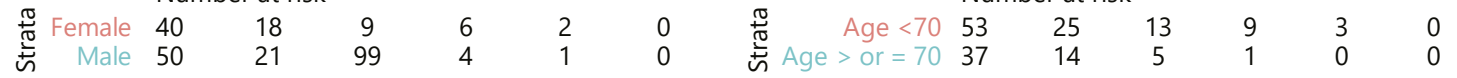
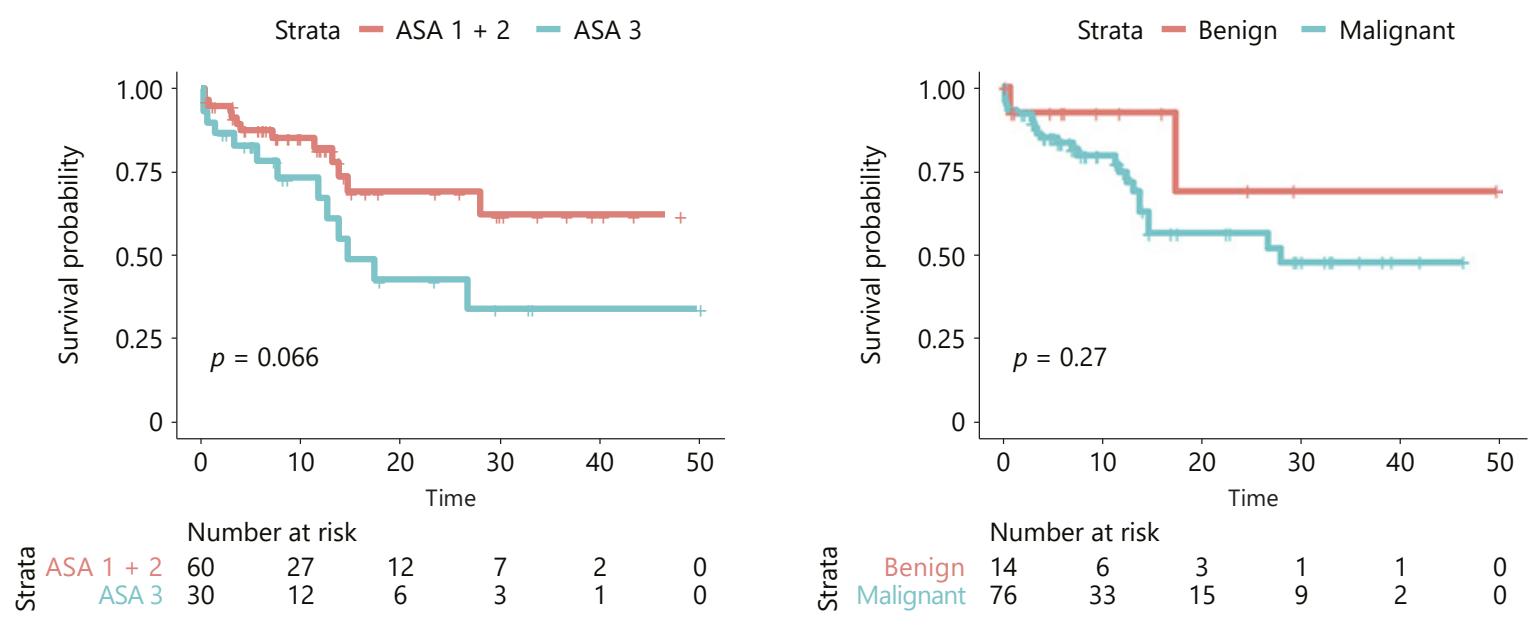

Fig. 3. Overall survival $(n=90)$. 

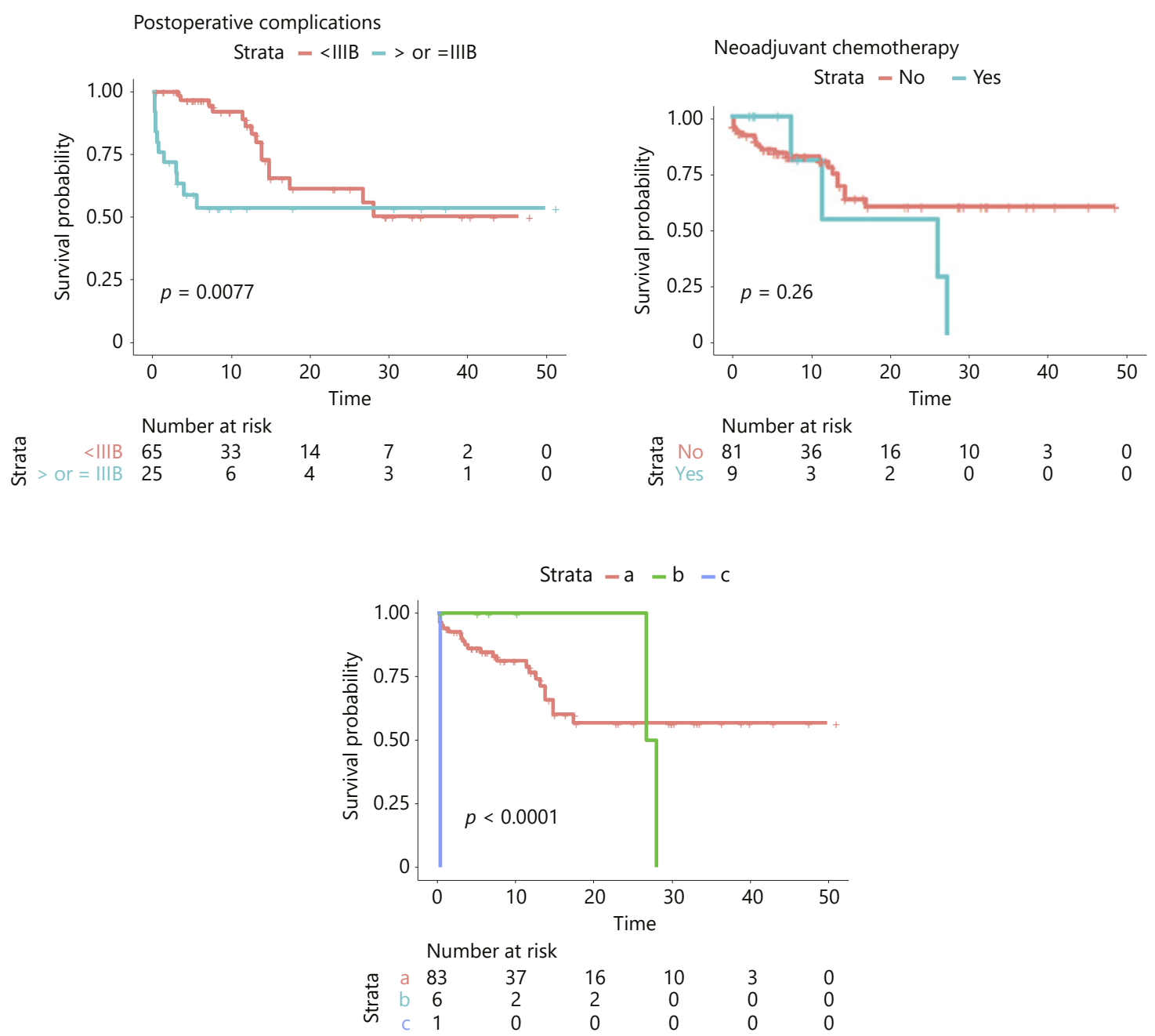

Fig. 4. Overall survival according to clinical variables: sex, age, ASA score, disease malignancy, neoadjuvant chemotherapy, postoperative complications, and type of surgery. a Total pancreatectomy or pancreaticoduodenectomy. b Distal pancreatectomy. c Pancreaticoduodenectomy with multivisceral resection $(n=90)$. IIIB, ClavienDindo class IIIb.

On the other hand, when we analyzed OS, age was no longer a determinant factor. With regard to body composition parameters, the results differed from those for 90day survival, and muscle radiation attenuation was the only significant variable where an increase in 1 unit was associated with a $6 \%$ reduction in estimated risk of death, independently of age, histology, and postoperative complications.

Finally, the 90-day survival and OS analyses were conducted only for patients with malignant disease, and similar results were obtained. In a model that adjusted for postoperative complications and age, VFA:SMA (HR
$2.02,95 \%$ CI $1.07-3.81, p=0.03)$ was significantly associated with 90-day survival. In a model adjusted for postoperative complications and age, muscle attenuation was significantly associated with OS (HR 0.94, 95\% CI 0.89$0.99, p=0.019)$.

\section{Discussion}

In this observational study performed in a single reference center for pancreatic surgery, we observed that body composition is a major determinant of the outcome of 

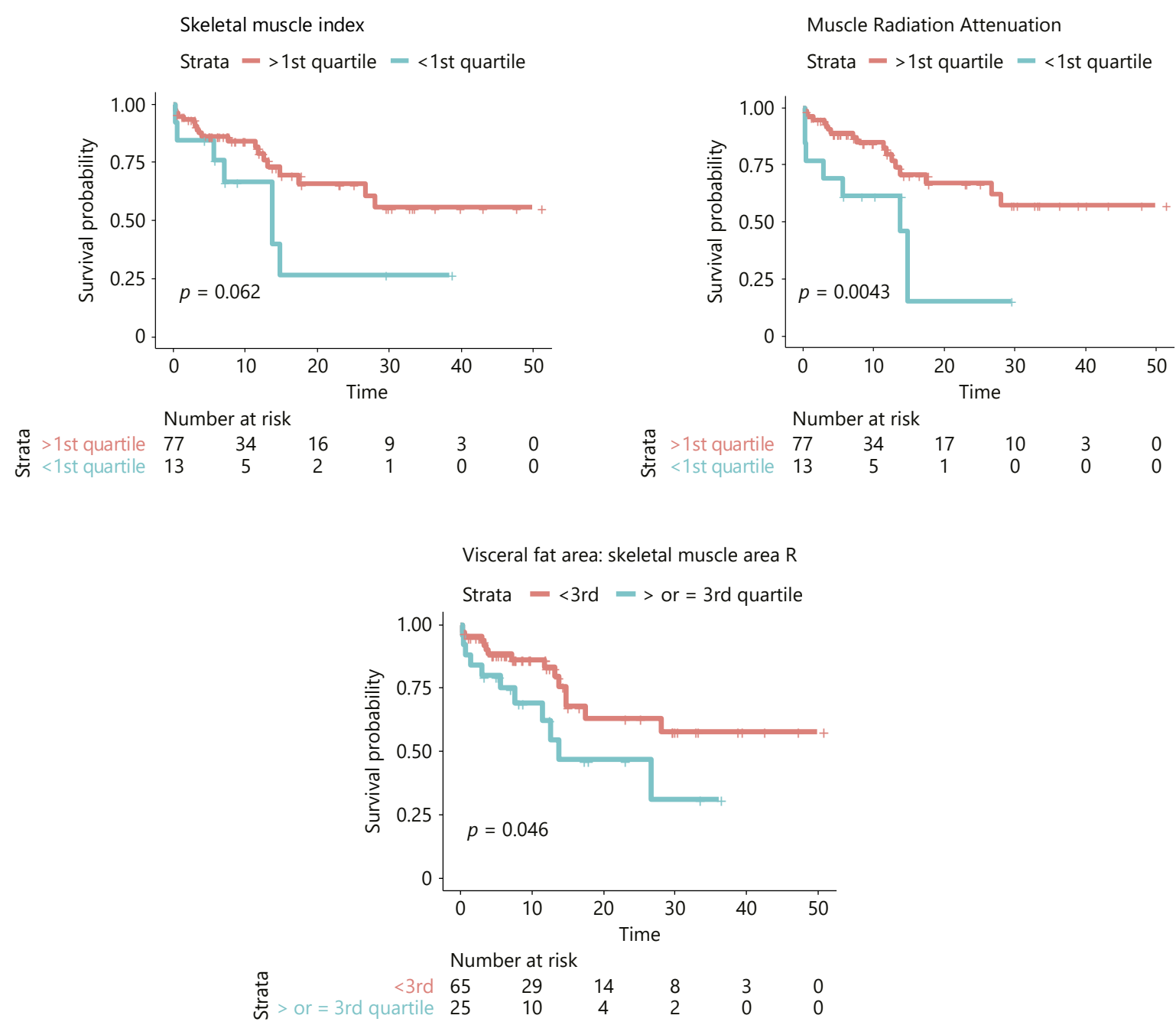

Fig. 5. Overall survival according to body composition variables dichotomized according to quartiles: skeletal muscle index, muscle radiation attenuation, and ratio of visceral fat area/skeletal muscle area (VFA:SMA) $(n=$ 90).

surgically treated patients. We found that, for predicting survival, the discrimination achieved with a model that includes 3 body composition parameters proved superior to a model with 4 conventional clinical variables such as age, ASA score, disease histology, and postoperative complications. With regard to postoperative complications, a major determinant of OS, we observed a significant association with VFA:SMA independently of ASA score. It is worth pointing out that, in our sample, only 2 patients met conventional criteria for sarcopenic obesity.

Considering the high morbidity and mortality associated with pancreatic surgery, our findings are highly relevant. Although age, ASA score, and disease stage are non-modifiable factors, we can certainly aim at modifying preoperative body composition, especially during neoadjuvant chemotherapy. This is being more frequently prescribed even in tumors which seem resectable upfront. Criteria for considering a tumor as borderline resectable have been recently expanded and, as of today, neoadjuvant chemo/chemoradiotherapy is now strongly recommended in a substantial proportion of operated patients, if not all [25-28]. This period usually lasts 6 months or even more, which is an excellent opportunity to intervene with combined programs of exercise and/or dietary intervention aimed at modifying body composition. 


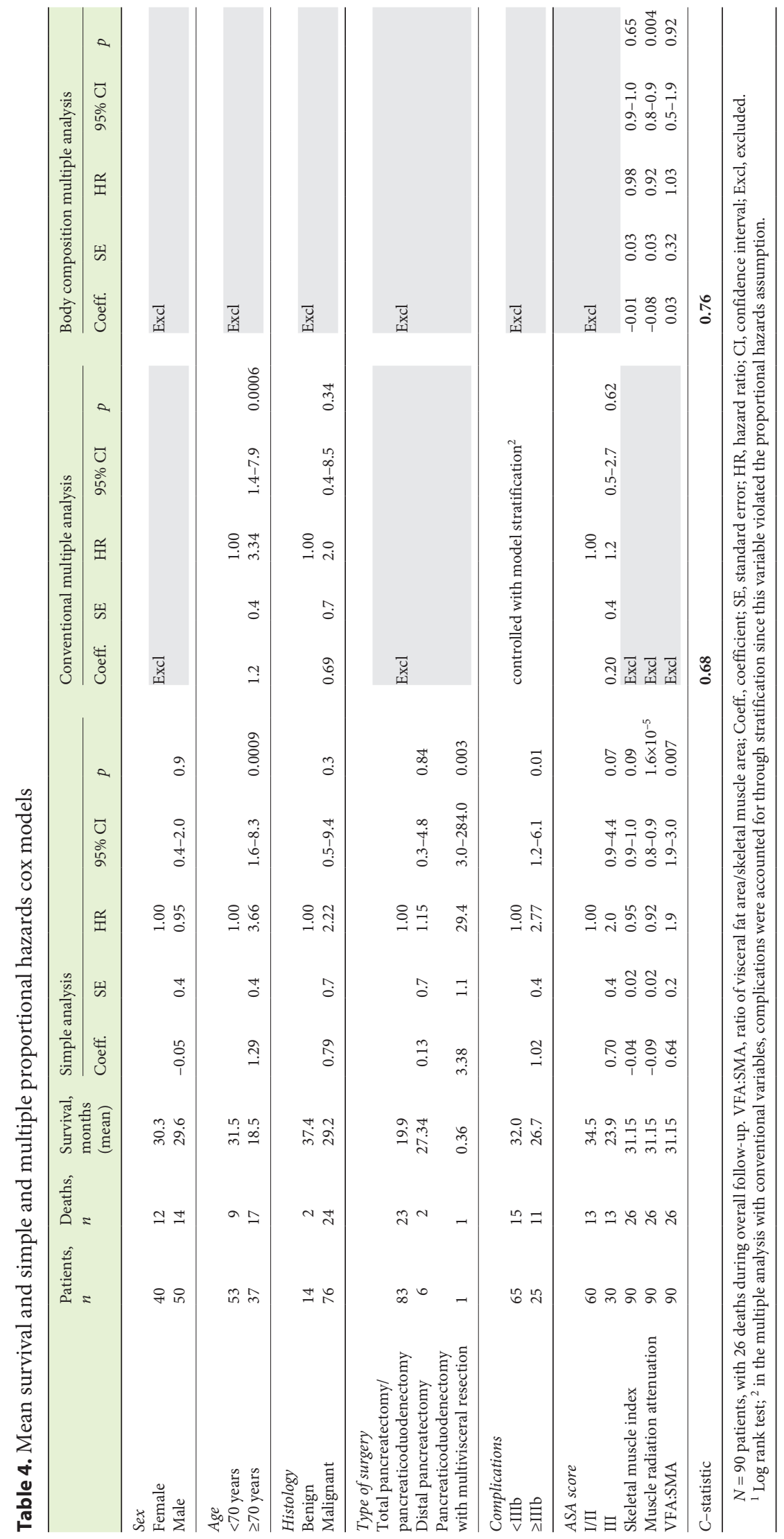


Table 5. Stratified Cox proportional hazards models of 90-day and overall survival

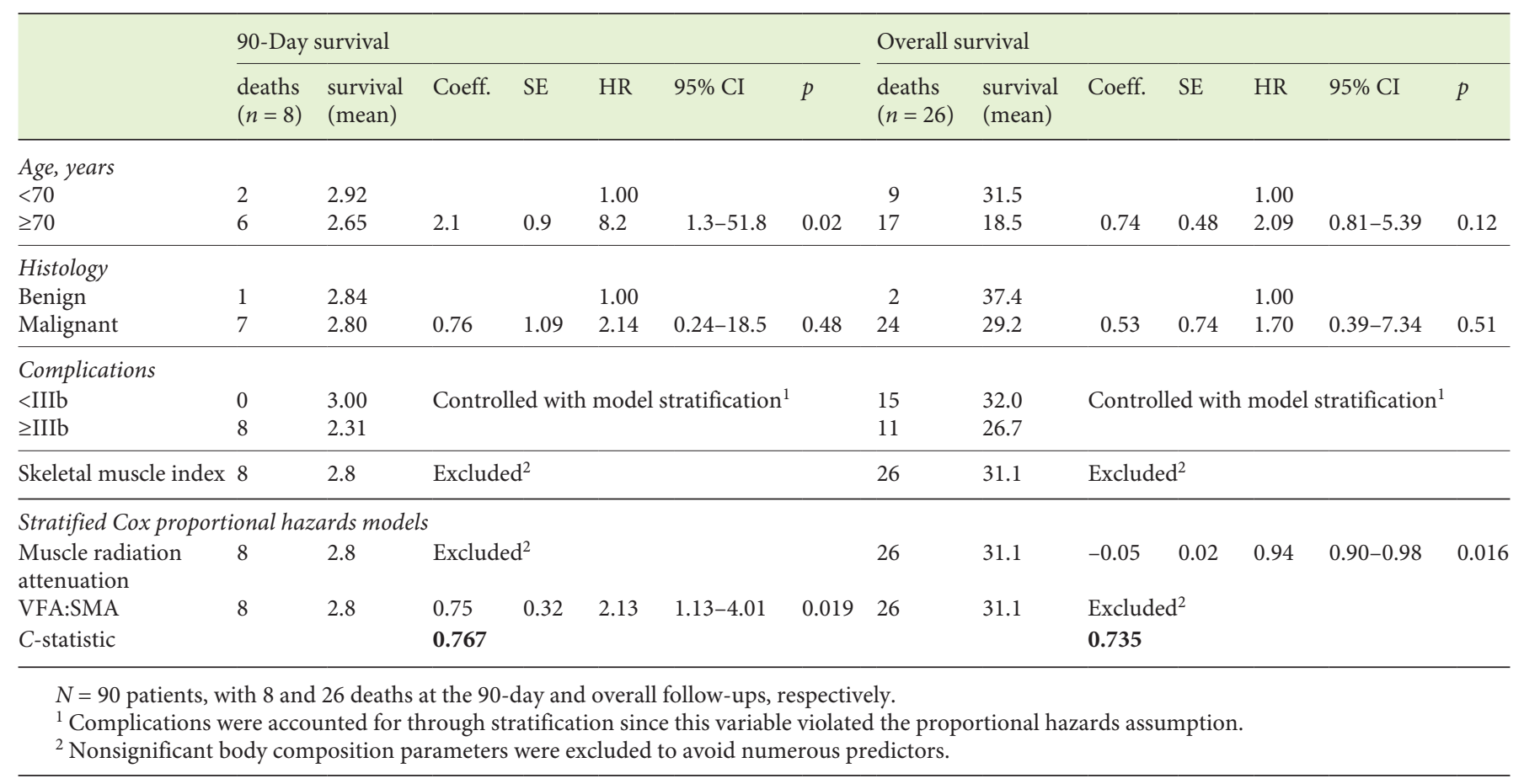

Most studies that have addressed the relationship between body composition and the clinical outcome of pancreatic surgery patients focused mainly on skeletal muscle tissue and OS, with contradictory results. The studies have approached this issue using different methods to tackle skeletal muscle tissue, namely L3 CT scan-derived sarcopenia $[4,10,16,29]$, SMA loss [30], accelerated loss of muscle mass [20], total psoas area $[1,11]$ and volume [5], which have been associated with shorter OS in pancreatic cancer patients submitted to surgery or palliative care.

In contrast, other studies failed to demonstrate such an association $[9,22]$, or were only able to show an association with sarcopenia if BMI was accounted for (which may be thought of as a proxy of body fatness) $[8,12]$. Some studies included patients submitted to curative and palliative procedures which obviously have different outcomes [13]. In this study, we enrolled patients submitted to curative surgery only; $84 \%$ had malignant tumors while the remaining ones had premalignant lesions, and all patients were treated by the same team of 3 surgeons. Although skeletal muscle per se was not associated with a worse prognosis, it is worth noting that both VFA:SMA and muscle attenuation, which incorporate both fat and skeletal muscle tissue, were strong determinants of postoperative complications, 90-day survival, and OS, respec- tively. This suggests that these body compartments should not be considered isolated as they seem to exert a joint influence on the final outcome.

Notably, most studies published so far have addressed OS; only a small number have investigated the effect of body composition on postoperative survival. Joglekar et al. [31] found that sarcopenia was an independent predictor of grade-III complications, but they did not analyze visceral fat or muscle attenuation. In our study series, VFA:SMA was independently associated with 90 -day survival and postoperative complications on multivariate analysis, while ASA score lost significance. Our findings are in line with the only published study to investigate the influence of VFA:SMA on 60-day mortality, and found that a VFA:SMA exceeding 3.2 and ASA III were the strongest predictors of mortality [3].

In our study, muscle radiation attenuation was found to be the most relevant body composition parameter associated with OS independently of age, postoperative complications, and disease histology. This result supports the hypothesis that muscle quality may be one of the most important body composition parameters influencing OS. In agreement with our results, van Dijk et al. [13] also found that low skeletal-muscle radiation attenuation was associated with worse OS and a high skeletal/ visceral adipose tissue index was related to an increased 
surgical-site infection rate. In this particular study, 50\% of patients had non-pancreatic cancer and $30 \%$ of them were submitted to palliative procedures which substantially increased the heterogeneity of the study population. In a recent study, Stretch et al. [9] found that myosteatosis was associated with an increase in postoperative complications but found no correlation between body composition and OS. Of note, the reported incidence of major postoperative complications and deaths in their study was exceedingly low, which could explain this lack of correlation. They concluded that sarcopenia and myosteatosis represent 2 separate and distinct clinical phenotypes, but they did not include VFA:SMA in their analysis.

To our knowledge, this is the first study examining the effect of body composition in its most holistic perspective including the ratios between visceral fat and skeletal muscle tissues in both postoperative outcomes and OS. Although well-powered prospective studies are still needed, our results suggest that muscle radiation attenuation may be an independent prognostic factor of OS and that VFA:SMA is significantly associated with 90 -day survival and postoperative complications.

\section{Statement of Ethics}

The study protocol was approved by the Scientific and Ethics committee of the HBA. The requirement for informed consent from patients was waived because of the retrospective design of the study.

\section{Disclosure Statement}

There were no conflicts of interest.

\section{Funding Sources}

There was no funding.

\section{Author Contributions}

S.V.: formal analysis and writing of original draft; M.P.C.S.: investigation and formal analysis; F.C. and C.C.: clinical data collection; L.A. and R.C.: computed tomography image acquisition and validation of processed images; M.G. and P.O.: investigation; R.M.: resources and supervision; V.E.B.: writing, review, and editing; M.C.: conceptualization, writing, review, and editing.

\section{References}

1 Peng P, Hyder O, Firoozmand A, Kneuertz P, Schulick RD, Huang D, et al. Impact of sarcopenia on outcomes following resection of pancreatic adenocarcinoma. J Gastrointest Surg. 2012 Aug;16(8):1478-86.

2 Pecorelli N, Nobile S, Partelli S, Cardinali L, Crippa S, Balzano G, et al. Enhanced recovery pathways in pancreatic surgery: state of the art. World J Gastroenterol. 2016 Jul;22(28): 6456-68.

3 Pecorelli N, Carrara G, De Cobelli F, Cristel G, Damascelli A, Balzano G, et al. Effect of sarcopenia and visceral obesity on mortality and pancreatic fistula following pancreatic cancer surgery. Br J Surg. 2016 Mar;103(4): 434-42.

4 El Amrani M, Vermersch M, Fulbert M, Prodeau M, Lecolle K, Hebbar M, et al. Impact of sarcopenia on outcomes of patients undergoing pancreatectomy: A retrospective analysis of 107 patients [Internet]. Medicine (Baltimore). 2018 Sep;97(39):e12076. Available from: http://www.ncbi.nlm.nih.gov/pubmed/ 30278487\%0Ahttp://www.pubmedcentral. nih.gov/articlerender.fcgi? artid= PMC6181530

5 Amini N, Spolverato G, Gupta R, Margonis GA, Kim Y, Kamel IR, et al. Impact Total Psoas Volume on Short- and Long-Term Outcomes in Patients Undergoing Curative Resection for Pancreatic Adenocarcinoma: a
New Tool to Assess Sarcopenia. J Gastrointest Surg. 2016;19(9):1593-602.

6 Jin WH, Mellon EA, Frakes JM, Murimwa GZ, Hodul PJ, Pimiento JM, et al. Impact of sarcopenia in borderline resectable and locally advanced pancreatic cancer patients receiving stereotactic body radiation therapy. J Gastrointest Oncol. 2018 Feb;9(1):24-34.

7 Weinberg MS, Shachar SS, Muss HB, Deal AM, Popuri K, Yu H, et al. Beyond sarcopenia: characterization and integration of skeletal muscle quantity and radiodensity in a curable breast cancer population. Breast J. 2018 May;24(3):278-84.

8 Ninomiya G, Fujii T, Yamada S, Yabusaki N, Suzuki K, Iwata N, et al. Carcinoma, Clinical impact of sarcopenia on prognosis in pancreatic ductal carcinoma. Int J Surg. 2017;39:4551.

9 Stretch C, Aubin JM, Mickiewicz B, Leugner D, Al-Manasra T, Tobola E, et al. Sarcopenia and myosteatosis are accompanied by distinct biological profiles in patients with pancreatic and periampullary adenocarcinomas. PLoS One. 2018 May;13(5):e0196235.

10 Choi MH, Yoon SB, Lee K, Song M, Lee IS, Lee MA, et al. Preoperative sarcopenia and post-operative accelerated muscle loss negatively impact survival after resection of pancreatic cancer. J Cachexia Sarcopenia Muscle. 2018 Apr;9(2):326-34.
11 Okumura S, Kaido T, Hamaguchi Y, Fujimoto Y. Impact of preoperative quality as well as quantity of skeletal muscle on survival after resection of pancreatic cancer. Surgery. 2015; 157(6):1088-98.

12 Tan BH, Birdsell LA, Martin L, Baracos VE, Fearon KC. Sarcopenia in an overweight or obese patient is an adverse prognostic factor in pancreatic cancer. Clin Cancer Res. 2009 Nov;15(22):6973-9.

13 van Dijk DP, Bakens MJ, Coolsen MM, Rensen SS, van Dam RM, Bours MJ, et al. Low skeletal muscle radiation attenuation and visceral adiposity are associated with overall survival and surgical site infections in patients with pancreatic cancer. J Cachexia Sarcopenia Muscle. 2017 Apr;8(2):317-26.

14 Dindo D, Demartines N, Clavien PA. Classification of surgical complications: a new proposal with evaluation in a cohort of $6336 \mathrm{pa}$ tients and results of a survey. Ann Surg. 2004 Aug;240(2):205-13.

15 Mourtzakis M, Prado CM, Lieffers JR, Reiman T, McCargar LJ, Baracos VE. A practical and precise approach to quantification of body composition in cancer patients using computed tomography images acquired during routine care [Internet]. Appl Physiol Nutr Metab. 2008 Oct;33(5):997-1006. Available from: http://www.nrcresearchpress.com/doi/ abs/10.1139/H08-075 
16 Martin L, Birdsell L, Macdonald N, Reiman T, Clandinin MT, McCargar LJ, et al. Cancer cachexia in the age of obesity: skeletal muscle depletion is a powerful prognostic factor, independent of body mass index. J Clin Oncol. 2013 Apr;31(12):1539-47.

17 Ribeiro-Filho FF, Faria AN, Azjen S, Zanella MT, Ferreira SR. Methods of estimation of visceral fat: advantages of ultrasonography. Obes Res. 2003 Dec;11(12):1488-94.

18 Prado CM, Lieffers JR, McCargar LJ, Reiman T, Sawyer MB, Martin L, et al. Prevalence and clinical implications of sarcopenic obesity in patients with solid tumours of the respiratory and gastrointestinal tracts: a populationbased study. Lancet Oncol. 2008 Jul;9(7):62935.

19 Yip C, Dinkel C, Mahajan A, Siddique M, Cook GJ, Goh V. Imaging body composition in cancer patients: visceral obesity, sarcopenia and sarcopenic obesity may impact on clinical outcome. Insights Imaging. 2015 Aug;6(4): 489-97.

20 Reisinger KW, Bosmans JW, Uittenbogaart M, Alsoumali A, Poeze M, Sosef MN, et al. Loss of Skeletal Muscle Mass During Neoadjuvant Chemoradiotherapy Predicts Postoperative Mortality in Esophageal Cancer Surgery. Ann Surg Oncol. 2015 Dec;22(13): 4445-52.
21 Di Sebastiano KM, Yang L, Zbuk K, Wong RK, Chow T, Koff D, et al. Accelerated muscle and adipose tissue loss may predict survival in pancreatic cancer patients: the relationship with diabetes and anaemia. Br J Nutr. 2013 Jan;109(2):302-12.

22 Rollins KE, Tewari N, Ackner A, Awwad A, Madhusudan S, Macdonald IA, et al. The impact of sarcopenia and myosteatosis on outcomes of unresectable pancreatic cancer or distal cholangiocarcinoma [Internet]. Clin Nutr. 2016 Oct;35(5):1103-9.

23 Kuwada K, Kuroda S, Kikuchi S, Yoshida R, Nishizaki M, Kagawa S, et al. Sarcopenia and Comorbidity in Gastric Cancer Surgery as a Useful Combined Factor to Predict Eventual Death from Other Causes [Internet]. Ann Surg Oncol. 2018 May;25(5):1160-6.

24 Frank E, Kerry L, Malchar D, Roichorl TA. Harrell Jr FE, Lee KL, Matchar DB, Reichert TA. Regression models for prognostic prediction: advantages, problems, and suggested solutions. Cancer Treat Rep. 2014 Jan; 1985: 1071-7.

25 Sabater L, Muñoz E, Roselló S, Dorcaratto D, Garcés-Albir M, Huerta M, et al. Borderline resectable pancreatic cancer. Challenges and controversies [Internet]. Cancer Treat Rev. 2018 Jul;68:124-35.

26 Isaji S, Mizuno S, Windsor JA, Bassi C, Fernández-Del Castillo C, Hackert T, et al. International consensus on definition and criteria of borderline resectable pancreatic ductal adenocarcinoma 2017. Pancreatology. 2018 Jan;18(1):2-11.
27 Conroy T, Hammel P, Hebbar M, Ben Abdelghani M, Wei AC, Raoul JL, et al.; Canadian Cancer Trials Group and the Unicancer-GIPRODIGE Group. FOLFIRINOX or Gemcitabine as Adjuvant Therapy for Pancreatic Cancer. N Engl J Med. 2018 Dec;379(25): 2395-406.

28 Tempero MA, Malafa MP, Al-Hawary M, Asbun $\mathrm{H}$, Bain A, Behrman SW, et al. Pancreatic adenocarcinoma, version 2.2017: clinical practice guidelines in Oncology. J Natl Compr Canc Netw. 2017 Aug;15(8):1028-61.

29 Kim Y, Kim J, Whang KY, Park Y. Impact of Conjugated Linoleic Acid (CLA) on Skeletal Muscle Metabolism. Lipids. 2016 Feb;51(2): 159-78.

30 Ní Bhuachalla ÉB, Daly LE, Power DG, Cushen SJ, MacEneaney P, Ryan AM. Computed tomography diagnosed cachexia and sarcopenia in 725 oncology patients: is nutritional screening capturing hidden malnutrition? J Cachexia Sarcopenia Muscle. 2018 Apr;9(2): 295-305.

31 Joglekar S, Asghar A, Mott SL, Benjamin E, Button AM, Clark EV, et al. Sarcopenia Is an Independent Predictor of Complications Following Pancreatectomy for Adenocarcinoma J. Surg Oncol. 2014 Feb;2015(111):771-5. 